\title{
STUDI PENGGUNAAN SENYAWA CaCl 2 DALAM MENURUNKAN KADAR SULFAT PADA LIMBAH PRODUKSI GARAM
}

\author{
Nike I. Nuzula*, Wiwit S.W. Pratiwi, Novi Indriyawati, Makhfud Efendy \\ Departemen Ilmu Kelautan, Fakultas Pertanian \\ Universitas Trunojoyo Madura \\ *email : nike.nuzula@trunojoyo.ac.id
}

Received 15 November 2020

Accepted 24 June 2021

\begin{abstract}
Abstrak
Bittern adalah salah satu hasil dari proses produksi garam yang saat ini pemanfaatannya belum maksimal. Hal ini dikarenakan banyaknya pengotor yang terkadung didalamnya. Sulfat merupakan pengotor tertinggi kedua dalam bittern. Penelitian ini dilakukan untuk mengikat sulfat pada bittern dengan menggunakan $\mathrm{CaCl}_{2} \cdot 2 \mathrm{H}_{2} \mathrm{O}$ dengan metode penambahan yang berbeda-beda. Variasi yang digunakan dalam penelitian ini adalah perbandingan mol antara bittern dengan Kristal $\mathrm{CaCl} 2$. Perbandingan mol terbaik antara bittern dengan Kristal $\mathrm{CaCl} 2$ didapatkan rasio sebesar 1: 0.9 dengan kadar sulfat sebesar $4.83 \mathrm{mg} / \mathrm{L}$, dimana kadar awal sulfat pada sampel bittern sebesar $41.257 \mathrm{~g} / \mathrm{L}$ atau setara dengan $41257 \mathrm{mg} / \mathrm{L}$.
\end{abstract}

Katakunci: Sulfat, $\mathrm{CaCl}_{2}$, Limbah Produksi Garam

\begin{abstract}
The traditional production of Salt was investigated has a secondary output called Bittern. Bittern has a lack of utilization since containing a many of impurities, one of them is Sulphate. This research aims to bind sulphate on bittern using $\mathrm{CaCl}_{2} \cdot 2 \mathrm{H}_{2} \mathrm{O}$ with different addition methods. The variation used in this study is the mole ratio between bittern and $\mathrm{CaCl} 2$ crystals. The best mole ratio between bittern and $\mathrm{CaCl} 2$ crystals obtained a ratio of 1: 0.9 with a sulphate level of $4.83 \mathrm{mg} / \mathrm{L}$, where the initial sulphate level in the bittern sample was $41.257 \mathrm{~g} / \mathrm{L}$ or equivalent to $41257 \mathrm{mg} / \mathrm{L}$.
\end{abstract}

Keywords: Sulfate, $\mathrm{CaCl}_{2}$, Bittern 


\section{Pendahuluan}

Madura merupakan pulau yang terletak di Jawa Timur dan dikenal dengan sebutan Pulau Garam, hal itu bukanlah sebutan semata karena empat Kabupaten yang ada di Madura dapat memproduksi garam dengan kualitas cukup bagus. Hal ini didukung dengan kondisi lingkungan di Madura yang sangat mendukung dalam proses pembuatan garam, rata-rata suhu di Madura berkisar 26,90 $\mathrm{C}$ dengan suhu udara maksimum rata-rata $30,5^{\circ} \mathrm{C}$. Pamekasan merupakan salah satu Kabupaten di Madura memiliki 2023,3 ha lahan tambak garam dan ini merupakan potensi yang sangat besar yang harus dikembangkan. Kecamatan Pademawu Kabupaten Pamekasan merupakan daerah terbesar kedua yang mempunyai luasan lahan tambak menyumbang $37,25 \%$ yaitu sebesar 753,7 Ha. Desa Padelegan adalah salah satu desa penghasil garam terbesar nomer 3 yang ada di Pulau Madura dan terdapat sebuah Marine Station Universitas Trunojoyo Madura (UTM).

Dalam proses produksi garam, selain menghasilkan garam juga menghasilkan limbah cair yang disebut dengan "Bittern". Bittern adalah cairan sisa padat dengan berat jenis $\geq 1,28 \mathrm{gm} / \mathrm{cm} 3$ yang diperoleh setelah pengendapan dan pemanenan garam $\mathrm{NaCl}$ dari air laut[1]. Kandungan yang terdapat pada bittern berupa mineral -mineral yang tidak ikut mengkristal pada saat proses evaporasi di meja garam, sehingga limbah cair ini berupa larutan jenuh yang kaya akan mineral dan elemen minor di dalamnya. Kadar kepekatan bittern yaitu $29{ }^{\circ}$ Be. Kadar kepekatan dapat berpengaruh terhadap naiknya konsentrasi mineral pada bittern[2]. Senyawa utama pada bittern yang banyak digunakan untuk industri yaitu magnesium[3]. Bittern sendiri, dapat dimanfaatkan secara langsung dan secara tidak langsung.

Dalam jurnal oleh Sembiring [4] disebutkan bahwa bittern dapat dimanfaatkan secara langsung sebagai suplemen minuman (nigari), pengawet ikan, campuran air berenam dan koagulan limbah industri[5]. Dalam pemanfaatan secacra tidak langsung di industri, bittern secara tidak langsung dapat dimanfaatkan, antara lain sebagai seperti bahan baku untuk pembuatan pupuk majemuk[6], bahan baku garam jenis kalium[7], dan sebagai bahan baku untuk produksi senyawa turunan magnesium antara lain magnesium oksida $(\mathrm{MgO})[8] ;[9]$, magnesium sulfat (MgSO4)[3][10] dan magnesium hidroksida $(\mathrm{Mg}(\mathrm{OH}) 2)$ [11][12].

Bittern yang berkualitas dapat menghasilkan kadar magnesium yang tinggi, sehingga perlu adanya pengikatan pada senyawa lain yang terkandung pada bittern. Senyawa yang paling berpengaruh pada bittern selain magnesium yaitu sulfat. Kandungan sulfat pada air laut maupun bittern yaitu tertinggi nomor 2 sebagai pengotor. Sulfat $\left(\mathrm{SO}_{4}\right)$ berasal dari sulfur yang terdegradasi secara anaerob sehingga membentuk hidrogen sulfida $\left(\mathrm{H}_{2} \mathrm{~S}\right)$. Sulfur tersebut berasal dari limbah organik yang dihasilkan dari pertanian, limbah ternak ataupun limbah industri, serta dari daerah perkotaan. Hidrogen sulfida akan teroksidasi oleh bakteri yang berfotosintesis sehingga menghasilkan sulfat. Sulfat tersebut akan terbawa oleh air hujan ataupun air tanah menuju muara sungai dan mengalir ke laut[13]. Penelitian ini akan dilakukan untuk pengikatan sulfat pada bittern menggunakan bahan kimia $\mathrm{CaCl}_{2} \cdot 2 \mathrm{H}_{2} \mathrm{O}$ (kalsium klorida dihidrat) dengan perlakuan penambahan yang berbeda-beda untuk mendapatkan hasil yang optimum dari penambahan bahan kimia tersebut yang akan digunakan.

\section{Metode Penelitian}

Pada penelitian ini, sampel bittern diambil dari tambak garam di desa Pandelegan, Kecamatan Pademawu, Pamekasan. Pengambilan sampel bittern dilakukan pada satu stasiun yaitu pada kolam kristalisasi. Analisa kandungan SO4 pada bittern secara turbidimetri menurut SNI tentang cara uji sulfat (SO42-) pada 
air dan air limbah secara turbidimetri[14]. Pengikatan sulfat (SO4) pada bittern menurut Mustafa dan Abdullah [9]dengan pembuatan larutan $\mathrm{CaCl}_{2} \cdot 2 \mathrm{H}_{2} \mathrm{O}$ yang akan ditambahkan pada bittern perlu dihitung menggunakan rumus mol, yaitu:

$$
\text { gram }=\mathrm{n} \times \mathrm{Mr}
$$

Keterangan:

Gram : massa suatu zat (gr)

n : nilai mol

$\mathrm{Mr} \quad$ : massa molekul relatif zat (gr/mol)

Penelitian ini menggunakan variasi pada penambahan $\mathrm{CaCl}_{2} \cdot 2 \mathrm{H}_{2} \mathrm{O}$ yang akan ditambahkan ke dalam bittern, dimana menggunakan perbandingan mol pada penambahan $\mathrm{CaCl}_{2} \cdot 2 \mathrm{H}_{2} \mathrm{O}$. Perbandingan mol yang digunakan antara $\mathrm{SO}_{4}$ dan $\mathrm{CaCl}_{2} .2 \mathrm{H}_{2} \mathrm{O}$ yaitu 1:0,9; $1: 0,95 ; 1: 1 ; 1: 1,05 ; 1: 1,1$.

Fungsi penambahan dan pengurangan mol tersebut untuk mengetahui jumlah $\mathrm{CaCl}_{2} \cdot 2 \mathrm{H}_{2} \mathrm{O}$ yang optimal untuk digunakan pada pengikatan sulfat $\left(\mathrm{SO}_{4}\right)$ pada bittern. Penambahan dilakukan secara perlahan-lahan, kemudian distirer dengan kecepatan konstan selama 1 jam sampai membentuk endapan dibagian bawah bittern. Menyaring larutan bittern yang telah muncul endapan dengan kertas saring yang telah dioven. 4. Uji kadar sulfat $\left(\mathrm{SO}_{4}\right)$ pada filtrat (bitter yang telah ditambahkan $\mathrm{CaCl}_{2} .2 \mathrm{H}_{2} \mathrm{O}$, namun endapan yang terbentuk pada larutan tersebut telah disaring) secara turbidimetri menurut SNI (2009) tentang cara uji sulfat $\left(\mathrm{SO}_{4}{ }^{2-}\right)$ pada air.

\section{Hasil dan Pembahasan}

Dalam proses produksi garam air laut tidak sepenuhya diproses menjadi garam, namun dari proses tersebut menghasilkan limbah cair ang disebut engan Bittern. Bittern sebagai limbah sisa memiliki nilai berat jenis $>/ 1,3 \mathrm{gm} / \mathrm{cm} 3$. Nilai ini diperoleh pada kondisi bittern telah diendakan dan diambil setelah panen $\mathrm{NaCl}$ dari air laut. Pada penelitian ini, sampel bitten diambil dari Desa Pandelegan Kecamatan Pademawu - Pamekasan, dengan kadar kepekatan bittern sebesar $29^{\circ}$ Be. Kadar kepekatan dapat berpengaruh terhadap naiknya konsentrasi mineral pada bittern[2]. Gambar 1 merupakan sampel bittern yang digunakan dalam penelitian ini.

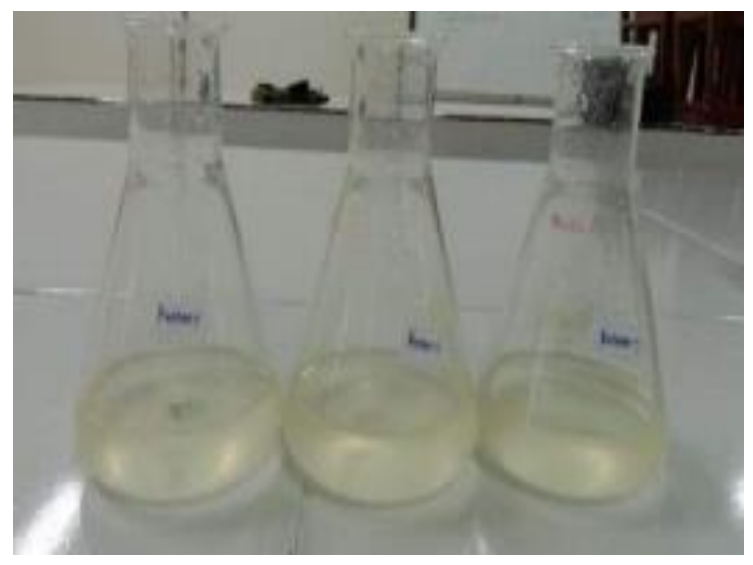

Gambar 1. Sampel bittern

Tahap pertama sampel bitten di saring dengan kertas saring whatman 42 agar menghasilkan filtrate yang bebas dari pengotor, seperti butiran tanah lempung, serta sisa kristal garam. Pada ketebalan 25 $\mathrm{cm}$ air pada tambak garam, lapisan bittern terdapat pada $10 \mathrm{~cm}$ teratas sedangkan sisa dibawahnya merupakan kristal garam.

Adanya pengotor yang memiliki ukuran partikel yang berbeda dapat mempengaruhi reaksi pengikatan senyawa kalsium sulfat[15]. Hasil filtrate bittern sebelum dan sesudah disaring dapat dilihat di Gambar 2. Pada gambar 2 terlihat bahwa hasil proses penyaringan mampu menghasilkan bittern yang lebih jernih. Sehingga dapat mengurangi zat pengotor yang ada pada sampel bittern.

Tahap kedua yaitu sampel bittern yang sudah disaring digunakan sebagai bahan baku untuk proses selanjutnya. Sample bitten dianalisa kadar sulfat dengan menggunakan metode SNI 6989.20 tahun 2009 yaitu metode pengujian kadar sulfat $\left(\mathrm{SO}_{4}{ }^{2-}\right)$ pada air dan air limbah secara turbidimetri. 


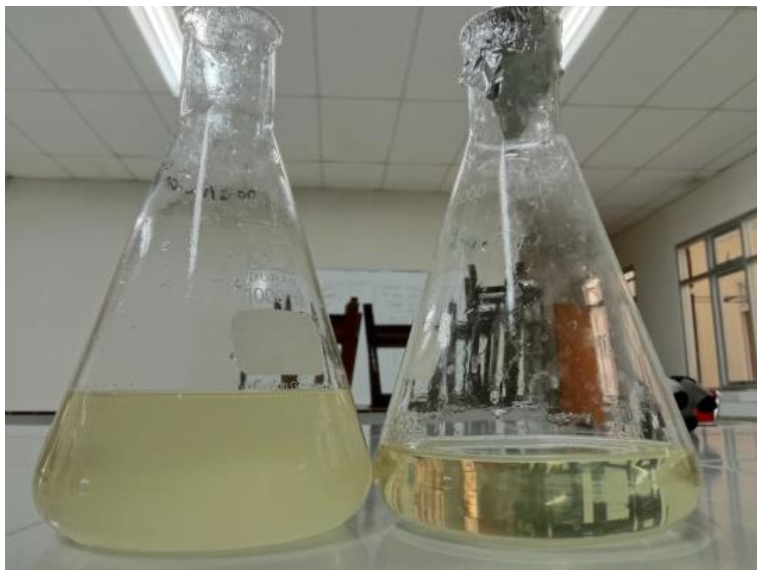

Gambar 2. (a) Sampel bittern sebelum penyaringan (b) sampel bittern sesudah penyaringan

Prinsip kerja pada metode ini yaitu ion sulfat dalam suasana asam bereaksi dengan kristal barium klorida ( $\mathrm{BaCl} 2)$ membentuk padatan barium sulfat (BaSO4) yang diukur dengan spektrofotometer UV-VIS 2600 Shimadzu menggunakan panjang gelombang $420 \mathrm{~nm}$. Pada penelitian ini kurva kalibrasi pada larutan standard didapatkan $\mathrm{y}=0.007 \mathrm{x}-0.007$ dengan $\mathrm{R} 2$ $=0.997$. Hasil analisa ini didapatkan kadar sulfat rata-rata pada bittern yaitu 41.257 g/L sesuai pada Tabel 1 .

Tabel 1. Rerata kadar sulfat pada bittern

\begin{tabular}{|c|c|}
\hline Sampel & ${\text { Kadar } \mathrm{SO}_{4}{ }^{2-}(\mathrm{g} / \mathrm{L})}$ \\
\hline 1 & 41.257 \\
\hline 2 & 40.500 \\
\hline 3 & 42.014 \\
\hline Rata-rata & 41.257 \\
\hline
\end{tabular}

Mustafa et al menyatakan kadar sulfat pada bittern di daerah Al-Basrah Salterns Irak sebesar $21.57 \mathrm{~g} / \mathrm{L}$ [9]. Pada bitter ini berasal dari sulfut yang terdegradasi dengan cara anaerob sehingga dapat membentuk hidrogen sulfida. Sulfur ini berasal dari limbah organik dari hasil pertanian, atau bisa juga dari limbah ternak, dari daerah perkotaan atau limbah industri. Sehingga, sulfat tersebut akan menuju muara sungai terbawa oleh hujan atau air tanah dan berakhir pada perairan laut. Tahap ketiga, sampel bittern ditambahkan kristal senyawa kalsium klorida dengan berbagai variasi mol, yaitu $1: 0.9 ; \quad 1 ; 0.95 ; \quad 1: 1 ; \quad 1 ; 1.05 ; \quad 1: 1.1$. Penambahan reagen kalsium klorida dihitung sesuai kadar sulfat yang terkandung dalam bitter dengan menggunakan prinsip stokiometri dan berdasarkan reaksi kimia dibawah ini,

$$
\begin{aligned}
& \mathrm{MgSO}_{4} \text { (aq) }+\mathrm{CaCl}_{2 \text { (aq) }} \rightarrow \mathrm{MgCl}_{2} \text { (aq) }+ \\
& \mathrm{CaSO}_{4}(\mathrm{~s})
\end{aligned}
$$

Pada reaksi tersebut, bittern dinyatakan sebagai senyawa magnesium sulfat, karena kandungan senyawa terbesar pada bittern yaitu magnesium sulfat (MgSO4) atau yang lebih dikenal dengan sebutan garam Epsom. Selain mengandung ion magnesium dan sulfat, bittern juga mengandung ion natrium dan klorida yang merupakan sisa hasil produksi garam yang belum mengkristal sempurna saat proses produksi garam berlangsung di tambak garam. Bittern juga mengandung ion kalsium, besi, kalium dan bromida[16][9]. Berdasarkan penelitian Musfata yang dimodifikasi, pada proses penambahan kalsium klorida distirer dalam waktu 60 menit, kemudian larutan didiamkan selama 24 jam dengan kondisi temperature ruang. Tujuan proses stirrer selama reaksi berlangsung, untuk mengoptimalkan laju reaksi antara bittern dengan reagen kalsium klorida, sedangkan tujuan didiamkan semalam hasil reaksi tersebut untuk memudahkan memisahkan antara padatan kalsium sulfat dengan filtrate. Gambar 3 menyajikan produk dari reaksi antara bittern dengan reagen kalsium krorida yang menghasilkan dua fase. 


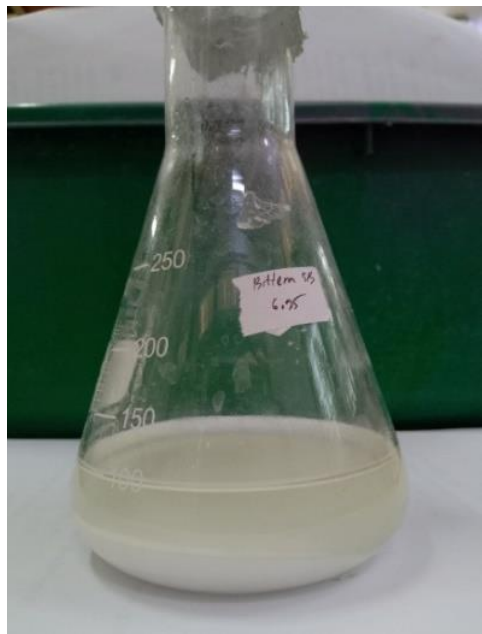

Gambar 3. Hasil reaksi bittern dengan kalsium klorida

Tahap keempat pada penelitian ini yaitu proses filtrasi untuk memisahkan padatan yang berupa senyawa kalsium sulfat dan filtrate. Untuk mempercepat proses filtrasi, tahap ini dibantu dengan alat vacuum pump, karena larutan yang dihasilkan kental dan pekat. Gambar 3 menyajikan hasil dari proses filtrasi. Filtrat tersebut dianalisa kadar sulfatnya untuk mengetahui berkurangnya kadar sulfat dari sampel awal. Hasil analisa kadar sulfat menunjukkan bahwa perbandingan mol antara bittern dan reagen kalsium klorida didapatkan hasil rasio terbaik untuk proses pemisahan kandungan sulfat pada sampel bittern yaitu 1: 0.9, dengan kadar sulfat sebesar $4.83 \mathrm{mg} / \mathrm{L}$, dimana kadar awal sulfat pada sampel bittern sebesar 41.257 $\mathrm{g} / \mathrm{L}$ atau setara dengan $41257 \mathrm{mg} / \mathrm{L}$.



Gambar 4. (a) filtrate (b) endapan $\mathrm{CaSO}_{4}$ Hasil kadar sulfat pada tiap pebandingan mol tersaji pada Gambar 5.
Kadar sulfat terbesar terdapat pada perbandingan mol 1: 1.05 yaitu 7.4165 $\mathrm{mg} / \mathrm{L}$ Hal ini mengindikasikan bahwa reagen kalsium klorida tidak bereaksi sempurna dengan ion sulfat pada sampel bittern. Mustafa et al menyatakan bahwa kadar senyawa $\mathrm{CaCl}_{2}$ dapat bereaksi dengan ratio Senyawa $\mathrm{CaCl}_{2}$ dan bittern adalah 1:1 sampai 1:1.1[9].

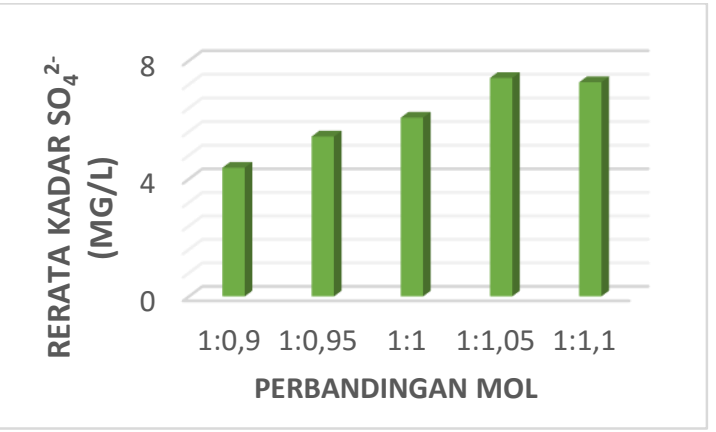

Gambar 5. Grafik hasil kadar sulfat tiap perbandingan mol

\section{Kesimpulan}

Penurunan kadar sulfat pada limbah proses produksi garam atau yang dikenal dengan sebutan bittern dapat dilakukan dengan menggunakan metode kimia dengan penambahan kristal senyawa kalsium klorida. Perbandingan mol terbaik antara bittern dengan Kristal $\mathrm{CaCl} 2$ didapatkan rasio sebesar 1: 0.9 dengan kadar sulfat sebesar $4.83 \mathrm{mg} / \mathrm{L}$, dimana kadar awal sulfat pada sampel bittern sebesar $41.257 \mathrm{~g} / \mathrm{L}$ atau setara dengan $41257 \mathrm{mg} / \mathrm{L}$.

\section{Saran}

Berdasarkan hasil yang telah didapat, dalam rangka pengempangan lebih jauh maka penelitian selanjutya dapat diberikan variasi dalam penambahan $\mathrm{CaCl}_{2}$ sehingga dapat ditentukan hasil yang efektif dan optimal. Serta dilakukan analisa ion lainnya bukan hanya sulfat saja, sehingga didapatkan informasi kandungan ion yang lebih lengkap. 


\section{Daftar Pustaka}

[1] Aral, H., B.D.Hill, and Sparrow, G. J., Salts from saline waters and value added products from the salts. CSIRO minerals, Victoria a. South Asutralia: Adelaide, 2004.

[2] R. Faizah, N., Liga I., Juwari., "Desain Pabrik Pupuk $\mathrm{MgSO}_{4} .7 \mathrm{H}_{2} \mathrm{O}$ dari Bittern," $J$. Tek. ITS, vol. VII, pp. 141-144, 2018.

[3] N. Hapsari, "Proses Pemisahan Ion Narium (Na) dan Magnesium (Mg) dalam Bittern (Buangan) Industri Garam dengan Membran Elektrodialisis," J. Tek. Kim., vol. III, pp. 192-198, 2008.

[4] N. Sembiring, "Pemanfaatan dan Usaha Sari Air Laut Berbasis Masyarakat," Jakarta, 2011.

[5] Sutiyono, "Pemanfaatan Bittern Sebagai Koagulan Pada Limbah Cair Industry Kertas," J. Tek. Kim., vol. 1, pp. 1-9, 2006.

[6] R. F. Sidik, "Variasi Produk Pupuk Majemuk Dari Limbah Garam (Bittern) Dengan Pengatur Basa Berbeda," J. Kelaut., vol. 6, pp. 1907-1931, 2013.

[7] and V. M. Ghosh, P.K., H. Joshi, H. Deraiya, R. Gandhi, K. Dave, J. Langalia, "Proccess for the Preparation of Magnesia (MgO)," U.S. Pat, vol. 7811535B2, p. 18, 2010.

[8] J. and S. M. Panda, "Proccess for the Production of Magnesium Oxide from Brine or Bittern," U.S. Pat, vol. 4370422, p. 25, 1983.

[9] A. M. K. and W. R. A. Mustafa, "Preparation Of High Purity Magnesium Oxide From Sea Bittern Residual From Nacl Production In AlBarsah Saltern, South Iraq," Iraqi Bull. Geol. Min., vol. 9, pp. 129-146, 2013.

[10] Sani, "Proses Pembuatan Magnesium Sulfat dari Bittern dan Asam Sulfat," UPN Jawa Timur, 2010.
[11] E. N. Alamdari, A., M. R.

Rahimpour, N. Esfandiari,

"Kinetics Of Magnesium

Hydroxide Precipitation From Sea

Bittern," Chem. Eng. Process., vol. 47, pp. 215-221, 2008.

[12] S. H. and M. S. M. Rafie, "Precipitation Of Nano-Magnesium Hydroxide From Bittern Using Ultrasound Irradiation," Der Chem. Sin., vol. 4, pp. 69-81.

[13] D. Hadiarti, "Proses Pemisahan Ion Narium (Na) dan Magnesium ( $\mathrm{Mg}$ ) dalam Bittern (Buangan) Industri Garam dengan Membran Elektrodialisis," J. Tek. Kim., vol. III, pp. 192-198, 2008.

[14] Standar Nasional Indonesia, "Air dan Limbah - Bagian 20: Cara Uji Sulfat $\left(\mathrm{SO}_{4}{ }^{2-}\right)$ secara Turbidimeri," SNI 6989.20:2009. 2009.

[15] Widjajanti, Kinetika Kimia. Yogyakarta: FMIPA UNY, 2007.

[16] Nuzula et al, "Laporan Penelitian Pemula," Universitas Trunojoyo, 2019. 